\title{
Influência da ordem e estádios da lactação no perfil bioquímico sangüíneo de cabras da raça Saanen
}

[Influence of parity and stage of lactation on the blood biochemical profile of Saanen goats]

\author{
A.V. Mundim ${ }^{1}$, A.S. Costa ${ }^{2}$, S.A.P. Mundim ${ }^{2}$, E.C. Guimarães ${ }^{3}$, F.S. Espindola ${ }^{3}$ \\ ${ }^{1}$ Aluno de pós-graduação - UFU - Uberlândia, MG \\ ${ }^{2}$ Médico veterinário autônomo \\ ${ }^{3}$ Universidade Federal de Uberlândia - Uberlândia, MG \\ Av. Pará, 1720 \\ 38400-902 - Uberlândia, MG.
}

\begin{abstract}
RESUMO
O perfil bioquímico sérico de cabras da raça Saanen lactantes foi investigado com o objetivo de analisar as variações fisiológicas e a influência da ordem e estádio da lactação, em função de possíveis biomarcadores, para monitorar o balanço energético, adequação metabólica durante a lactação. Foram analisadas amostras de sangue de cabras lactantes de primeira, segunda e terceira lactação, colhidas da veia jugular em tubo vacutainer com gel separador para obtenção de soro e determinação das concentrações de proteínas, metabólitos, minerais e enzimas. Observou-se influência da ordem de lactação nos valores das proteínas totais, glicose, triglicérides, cálcio total e ionizado, aspartato aminotransferase (AST), fosfatase alcalina e dos estádios da lactação nas concentrações séricas das proteínas totais, glicose, triglicérides, magnésio, AST e fosfatase alcalina. Conclui-se que glicose, triglicérides, cálcio total, cálcio ionizado, magnésio, AST e fosfatase alcalina são biomarcadores eficazes para detecção de desbalanço energético e mineral em cabras lactantes.
\end{abstract}

Palavras-chave: cabras Saanen, perfil bioquímico, lactação

\begin{abstract}
The serum biochemical profile of Saanen dairy goat was investigated with the purpose of analyzing the physiological variations and the influence of lactation order and stage in terms of possible biomarkers to monitor the energetic balance and the metabolic adequacy during lactation. Blood samples were taken from lactating goats at first, second and third lactation. They were collected from the jugular vein in a vacutainer tube with separator gel to obtain sera and to determine protein, metabolite, mineral and enzyme concentrations. The lactation order influence was observed on total protein, glucose, triglycerides, total and ionized calcium, aspartate aminotransferase (AST) and alkaline phosphatase values and the lactation stages on serum concentrations of total proteins, glucose, triglycerides and magnesium, AST and alkaline phosphatase. It was inferred that glucose, triglycerides, total calcium, ionized calcium, magnesium, AST and alkaline phosphatase are effective biomarkers to detect the energetic and mineral imbalance in Saanen dairy goats.
\end{abstract}

Keywords: goat Saanen, biochemical profile, lactation

Recebido em 19 de abril de 2005

Aceito em 2 de fevereiro de 2007

E-mail: avmundim@demea.ufu.br 


\section{INTRODUÇÃO}

A exploração de caprinos, voltada para a produção de leite e derivados, apresenta acentuado crescimento no país devido à crescente demanda e à melhor remuneração obtida com os produtos lácteos. Como conseqüência, intensificaram-se os sistemas de exploração para alcançar a rentabilidade almejada, o que aumentou, também, os riscos de ocorrência de transtornos metabólicos na cabra, em função de desequilíbrios entre o aporte de nutrientes ao organismo, a capacidade de metabolização desses componentes e o nível de produção alcançado.

Sabe-se que as variações fisiológicas podem ser influenciadas pela raça, idade, sexo, atividade física, condições nutricionais e ambientais, regime de manejo, estádio reprodutivo e da lactação, estação do ano e produção leiteira (Avidar et al., 1981; Kaneko, 1989; Gomide et al., 2004).

Durante a lactação, é grande o aporte de glicose, para a síntese de lactose pelos alvéolos, de aminoácidos, para a síntese de caseína e lactoalbumina, e de ácidos graxos para a síntese de gordura no leite. Rebanhos de alta produção de leite necessitam de adequado balanço nutricional, especialmente no início da lactação. Ressalta-se que até 60 dias pós-parto, a cabra atinge o pico de produção de leite, mesmo se o consumo de alimento estiver deprimido, o que resulta em mobilização de suas reservas corporais para suprir os elevados requisitos metabólicos. Segundo Barros et al. (1992), no início da lactação a cabra encontra-se em balanço energético negativo e durante a lactação há declínio linear na produção de leite de aproximadamente $10 \%$ ao mês.

A avaliação clínica de rebanhos com problemas reprodutivos e de produção pode ser complementada pela análise do perfil metabólico dos animais. No estudo dos parâmetros bioquímicos do sangue, glicose, colesterol e triglicérides representam o metabolismo energético; uréia, proteínas totais, albumina e globulinas representam o metabolismo protéico; cálcio, fósforo inorgânico, magnésio, ferro, sódio e potássio representam os minerais. A atividade das enzimas aspartato aminotransferase (AST), gama glutamiltransferase (GGT), alanina aminotransferase (ALT) e fosfatase alcalina (FAL) são biomarcadores sangüíneos de grande valor para avaliar distúrbios metabólicos, funcionamento hepático, alterações ósseas e desbalanço na relação cálcio:fósforo, embora seja a ALT de pouco valor diagnóstico em ruminantes (González e Silva, 2003).

Estudos da bioquímica sangüínea são importantes para se entender a relação entre os componentes metabólicos e nutricionais em rebanhos leiteiros. A escassez de estudos sobre a bioquímica sangüínea de cabras lactantes, no país, norteou este trabalho cujo objetivo foi estimar as variações fisiológicas e a influência da ordem e estádios da lactação sobre o perfil bioquímico sangüíneo de cabras Saanen lactantes.

\section{MATERIAL E MÉTODOS}

Utilizaram-se 123 cabras da raça Saanen lactantes, sendo 40 de primeira, 43 de segunda e 40 de terceira lactação, ordenhadas mecanicamente duas vezes ao dia, com produção média de $2 \mathrm{~kg}$ de leite/dia. Os animais, mantidos em confinamento, receberam silagem e concentrado no cocho, diariamente e suplementação mineral.

Coletaram-se, por venipuntura da jugular, $6 \mathrm{ml} \mathrm{de}$ sangue, em tubo vacutainer com gel separador para obtenção de soro. As amostras de sangue foram transportadas imediatamente em caixas isotérmicas ao laboratório, centrifugadas a $720 \mathrm{~g}$ durante cinco minutos para obtenção de soro e processamento das análises.

Determinaram-se as concentrações séricas de proteínas totais - método biureto; albumina - verde de bromocresol; glicose, triglicérides, colesterol e ácido úrico - método enzimático; uréia - enzimático UV, cálcio total, magnésio - colorimétrico; fósforo - UV de ponto final; sódio, potássio e cloretos íons eletrodo seletivo; ferro - Goodwin modificado; alanina aminotransferase (ALT) e aspartato aminotransferase (AST) - cinético UV-IFCC; fosfatase alcalina - cinético otimizado e gama glutamiltransferase (GGT) - cinético. Todas as análises foram processadas em analisador automático ${ }^{1}$, utilizando kits específicos ${ }^{2}$. Os valores

${ }^{1}$ Cobas Integra, Roche Diagnostics - Basel, Switzerland.

${ }^{2}$ Roche Diagnostics - Basel, Switzerland. 
das globulinas foram obtidos pela diferença entre os valores das proteínas totais e albumina, e o do cálcio ionizado calculado segundo recomendação da Analisa ... (2002).

Utilizou-se um delineamento inteiramente ao acaso. $\mathrm{Na}$ análise de variância, agruparam-se os animais de acordo com a ordem de lactação primeira, segunda e terceira lactações-, e estádio da lactação - inicial, até 100 dias e final, acima de 100 dias de lactação. Calcularam-se as médias aritméticas, desvios-padrão e valores mínimos e máximos.

\section{RESULTADOS E DISCUSSÃO}

Os valores dos parâmetros bioquímicos séricos estão relacionados nas Tab. 1, 2 e 3 .

A maioria dos valores (Tab. 1) permaneceu dentro dos limites ou ficou próximo dos valores descritos por Kaneko (1989) e Carlson (1994). Embora a uréia tenha apresentado concentrações mais elevadas que as citadas por Kaneko (1989) e Carlson (1994), ainda assim permaneceram dentro do intervalo de 34,94 a $61,45 \mathrm{mg} / \mathrm{dl}$, observado por Halar et al. (1996).

A relação Ca:P manteve-se no intervalo de 1:1 a 2:1, descrita por McDowell (1992) como sendo a proporção sérica fisiológica para suprir as necessidades de crescimento, formação óssea e manutenção da produção de leite. As concentrações séricas de ferro são pouco avaliadas em cabras lactantes, sendo um parâmetro importante em caprinos jovens por serem mais propensos às anemias ferroprivas. Neste estudo, seu valor médio manteve-se entre 16 a $34 \mu \mathrm{mol} / 1$, observado por Raviart et al. (1987).

Tabela 1. Médias, desvios-padrão (DP), valores mínimos, máximos e referenciais dos parâmetros bioquímicos séricos de 123 cabras lactantes da raça Saanen

\begin{tabular}{|c|c|c|c|c|c|}
\hline \multirow{2}{*}{\multicolumn{2}{|c|}{ Parâmetro bioquímico }} & \multirow{3}{*}{$\begin{array}{l}\text { Média } \pm D P \\
7,09 \pm 0,49\end{array}$} & \multicolumn{3}{|c|}{ Valores } \\
\hline & & & Mínimo & Máximo & Referenciais* \\
\hline Proteínas totais & $\mathrm{g} / \mathrm{dl}$ & & 6,10 & 8,40 & $6,4-7,0$ \\
\hline Albumina (A) & $\mathrm{g} / \mathrm{dl}$ & $3,07 \pm 0,41$ & 1,90 & 3,70 & $2,7-3,9$ \\
\hline Globulinas (G) & $\mathrm{g} / \mathrm{dl}$ & $4,02 \pm 0,62$ & 2,90 & 5,70 & $2,7-4,1$ \\
\hline Relação A/G & & $0,79 \pm 0,19$ & 0,37 & 1,13 & $0,63-1,26$ \\
\hline Glicose & $\mathrm{mg} / \mathrm{dl}$ & $52,56 \pm 6,07$ & 37,00 & 69,00 & $50,0-75,0$ \\
\hline Uréia & $\mathrm{mg} / \mathrm{dl}$ & $52,79 \pm 12,59$ & 28,00 & 104,00 & $10,0-20,0$ \\
\hline Triglicérides & $\mathrm{mg} / \mathrm{dl}$ & $14,84 \pm 6,00$ & 6,00 & 32,00 & --------- \\
\hline Colesterol & $\mathrm{mg} / \mathrm{dl}$ & $115,16 \pm 23,36$ & 70,00 & 175,00 & $80,0-130,0$ \\
\hline Ácido úrico & $\mathrm{mg} / \mathrm{dl}$ & $0,34 \pm 0,14$ & 0,10 & 0,80 & $0,3-1,0$ \\
\hline Cálcio total & $\mathrm{mg} / \mathrm{dl}$ & $8,70 \pm 0,82$ & 6,40 & 10,30 & $8,9-11,7$ \\
\hline Cálcio ionizado & $\mathrm{mg} / \mathrm{dl}$ & $4,87 \pm 0,47$ & 3,40 & 5,80 & --------- \\
\hline Fósforo & $\mathrm{mg} / \mathrm{dl}$ & $6,44 \pm 1,60$ & 3,30 & 12,50 & 6,5 \\
\hline Relação Ca/P & & $1,44 \pm 0,40$ & 0,53 & 2,64 & --------- \\
\hline Ferro & $\mu \mathrm{g} / \mathrm{dl}$ & $126,23 \pm 32,02$ & 53,00 & 254,00 & --------- \\
\hline Magnésio & $\mathrm{mg} / \mathrm{dl}$ & $3,00 \pm 0,44$ & 2,20 & 4,60 & $2,8-3,6$ \\
\hline Sódio & $\mathrm{mEq} / 1$ & $142,83 \pm 2,90$ & 133,00 & 149,00 & $142,0-155,0$ \\
\hline Cloretos & $\mathrm{mEq} / \mathrm{l}$ & $106,45 \pm 2,47$ & 98,00 & 112,00 & $99,0-110,3$ \\
\hline Potássio & $\mathrm{mEq} / 1$ & $4,23 \pm 0,37$ & 3,40 & 5,40 & $3,5-6,7$ \\
\hline Amilase & $\mathrm{U} / 1$ & $25,22 \pm 8,34$ & 11,00 & 62,00 & --------- \\
\hline AST & $\mathrm{U} / 1$ & $102,40 \pm 32,73$ & 56,00 & 247,00 & $167,0-513,0$ \\
\hline ALT & $\mathrm{U} / 1$ & $19,43 \pm 3,31$ & 11,00 & 28,00 & $24,0-83,0$ \\
\hline Fosfatase alcalina & $\mathrm{U} / 1$ & $72,62 \pm 46,05$ & 27,00 & 344,00 & $93,0-386,0$ \\
\hline GGT & $\mathrm{U} / 1$ & $37,47 \pm 12,17$ & 23,00 & 111,00 & $20,0-56,0$ \\
\hline
\end{tabular}

*Kaneko (1989) e Carlson (1994)

$\mathrm{AST}=$ aspartato aminotransferase, $\mathrm{ALT}=$ alanina aminotransferase, $\mathrm{GGT}=$ gama glutamiltransferase . 
Com relação à atividade das enzimas, a GGT manteve-se dentro dos limites citados por Kaneko (1989), a AST, ALT, fosfatase alcalina apresentaram valores médios inferiores aos descritos por Kaneko (1989) e Carlson (1994), e a amilase sérica manteve-se entre 12,1 a 37,1U/1, observado por Halar et al. (1996).

As diferenças entre os valores da uréia, AST, ALT e fosfatase alcalina observados neste estudo e os dados da literatura possivelmente são decorrentes de variações fisiológicas individuais, idade dos animais, manejo, produção de leite e fatores ambientais.

A menor concentração de proteínas totais observada nos animais de terceira lactação (Tab. 2), não é um achado expressivo, uma vez que este valor permaneceu dentro dos limites considerados fisiológicos para a espécie caprina, e resultou de concentrações mais baixas de albumina e globulinas. As menores concentrações séricas de glicose nas cabras de segunda e terceira lactações são decorrentes do maior aporte desse metabólito pela glândula mamária, para obtenção de energia e síntese da lactose, pois sabe-se que estas são as ordens de maior produção de leite. Esse resultado condiz com os de Kappel et al. (1984), que observaram valores significativamente mais elevados de glicose em vacas de primeira lactação comparadas às de segunda e terceira lactações. Segundo Ingraham e Kappel (1988), a concentração sérica de glicose apresenta correlação negativa com a produção de leite.

Tabela 2. Médias e desvios-padrão (DP) dos parâmetros bioquímicos séricos de cabras lactantes da raça Saanen, de acordo com a ordem de lactação

\begin{tabular}{|c|c|c|c|c|}
\hline \multicolumn{2}{|l|}{ Parâmetros bioquímicos } & \multirow{2}{*}{$\begin{array}{c}\begin{array}{c}1^{\text {a }} \text { lactação } \\
(\mathrm{n}=40)\end{array} \\
\text { Média } \pm \mathrm{DP}\end{array}$} & \multirow{2}{*}{$\begin{array}{c}2^{\text {a }} \begin{array}{c}\text { lactação } \\
(\mathrm{n}=43)\end{array} \\
\text { Média } \pm \mathrm{DP}\end{array}$} & \multirow{2}{*}{$\begin{array}{c}\begin{array}{c}3^{\mathrm{a}} \text { lactação } \\
(\mathrm{n}=40)\end{array} \\
\text { Média } \pm \mathrm{DP}\end{array}$} \\
\hline & & & & \\
\hline Proteínas totais & $\mathrm{g} / \mathrm{dl}$ & $7,05 \pm 0,49 \mathrm{ab}$ & $7,22 \pm 0,51 \mathrm{a}$ & $6,96 \pm 0,41 b$ \\
\hline Albumina (A) & $\mathrm{g} / \mathrm{dl}$ & $2,99 \pm 0,44 \mathrm{a}$ & $3,17 \pm 0,37 \mathrm{a}$ & $3,01 \pm 0,41 \mathrm{a}$ \\
\hline Globulinas (G) & $\mathrm{g} / \mathrm{dl}$ & $4,06 \pm 0,74 \mathrm{a}$ & $4,05 \pm 0,59 \mathrm{a}$ & $3,95 \pm 0,52 \mathrm{a}$ \\
\hline Relação A/G & & $0,77 \pm 0,22 \mathrm{a}$ & $0,81 \pm 0,18 \mathrm{a}$ & $0,78 \pm 0,18 \mathrm{a}$ \\
\hline Glicose & $\mathrm{mg} / \mathrm{dl}$ & $55,84 \pm 5,63 \mathrm{a}$ & $50,72 \pm 6,25 b$ & $51,84 \pm 4,97 b$ \\
\hline Uréia & $\mathrm{mg} / \mathrm{dl}$ & $53,03 \pm 12,47 a$ & $51,23 \pm 11,66 \mathrm{a}$ & $54,71 \pm 14,00 \mathrm{a}$ \\
\hline Triglicérides & $\mathrm{mg} / \mathrm{dl}$ & $15,84 \pm 6,83 \mathrm{ab}$ & $13,09 \pm 5,19 b$ & $16,26 \pm 5,74 a$ \\
\hline Colesterol & $\mathrm{mg} / \mathrm{dl}$ & $110,39 \pm 25,01 \mathrm{a}$ & $116,65 \pm 20,04 a$ & $117,87 \pm 25,88 \mathrm{a}$ \\
\hline Ácido úrico & $\mathrm{mg} / \mathrm{dl}$ & $0,32 \pm 0,10 \mathrm{a}$ & $0,36 \pm 0,15 a$ & $0,37 \pm 0,17 \mathrm{a}$ \\
\hline Cálcio total & $\mathrm{mg} / \mathrm{dl}$ & $9,11 \pm 0,79 a$ & $8,79 \pm 0,73 a$ & $8,17 \pm 0,71 b$ \\
\hline Cálcio ionizado & $\mathrm{mg} / \mathrm{dl}$ & $5,16 \pm 0,40 \mathrm{a}$ & $4,86 \pm 0,41 b$ & $4,62 \pm 0,46 \mathrm{c}$ \\
\hline Fósforo & $\mathrm{mg} / \mathrm{dl}$ & $6,74 \pm 1,45 \mathrm{a}$ & $6,18 \pm 1,37 \mathrm{a}$ & $6,51 \pm 2,00 \mathrm{a}$ \\
\hline Relação $\mathrm{Ca} / \mathrm{P}$ & & $1,43 \pm 0,39 a$ & $1,50 \pm 0,38 \mathrm{a}$ & $1,38 \pm 0,44 \mathrm{a}$ \\
\hline Ferro & $\mu \mathrm{g} / \mathrm{dl}$ & $120,90 \pm 33,44 a$ & $132,02 \pm 30,84 a$ & $123,52 \pm 31,91 \mathrm{a}$ \\
\hline Magnésio & $\mathrm{mg} / \mathrm{dl}$ & $3,00 \pm 0,43 \mathrm{a}$ & $3,12 \pm 0,44 \mathrm{a}$ & $2,98 \pm 0,43 \mathrm{a}$ \\
\hline Sódio & $\mathrm{mEq} / 1$ & $143,00 \pm 3,03 \mathrm{a}$ & $142,28 \pm 2,39 a$ & $143,42 \pm 3,32 \mathrm{a}$ \\
\hline Cloretos & $\mathrm{mEq} / \mathrm{l}$ & $106,35 \pm 2,59 a$ & $106,30 \pm 2,13 \mathrm{a}$ & $106,74 \pm 2,80 \mathrm{a}$ \\
\hline Potássio & $\mathrm{mEq} / 1$ & $4,20 \pm 0,38 \mathrm{a}$ & $4,27 \pm 0,33 \mathrm{a}$ & $4,18 \pm 0,43 a$ \\
\hline Amilase & $\mathrm{U} / 1$ & $24,16 \pm 7,54 \mathrm{a}$ & $27,81 \pm 8,95 \mathrm{a}$ & $24,68 \pm 8,36 \mathrm{a}$ \\
\hline AST & $\mathrm{U} / 1$ & $96,87 \pm 26,30 b$ & $112,81 \pm 41,55 \mathrm{a}$ & $93,48 \pm 18,28 b$ \\
\hline ALT & $\mathrm{U} / 1$ & $19,26 \pm 3,65 \mathrm{a}$ & $19,79 \pm 3,20 \mathrm{a}$ & $19,10 \pm 3,17 \mathrm{a}$ \\
\hline Fosfatase alcalina & $\mathrm{U} / 1$ & $103,27 \pm 57,25 \mathrm{a}$ & $64,84 \pm 40,12 b$ & $52,06 \pm 16,72 b$ \\
\hline GGT & $\mathrm{U} / 1$ & $37,74 \pm 11,06 \mathrm{a}$ & $39,49 \pm 15,22 \mathrm{a}$ & $34,39 \pm 7,11 \mathrm{a}$ \\
\hline
\end{tabular}

$\overline{\mathrm{AST}}=$ aspartato aminotransferase, $\mathrm{ALT}=$ alanina aminotransferase, $\mathrm{GGT}=$ gama glutamiltransferase.

Médias na linha seguidas de letras distintas diferem entre si $(\mathrm{P}<0,05)$. 
A concentração de triglicérides foi significativamente menor nos animais de segunda lactação (Tab. 2). Essa redução é um reflexo do aumento da produção de leite durante a segunda lactação, da menor reserva de ácidos graxos livres disponíveis, da lipólise para obtenção de energia e maior aporte de triglicérides circulantes pela glândula mamária para síntese de gordura do leite. As fêmeas de segunda lactação são as mais propensas aos distúrbios metabólicos como desbalanços energéticos e cetose subclínica. Cerca de dois terços dos triglicérides circulantes são precursores lipídicos sangüíneos utilizados na síntese de gordura do leite (Marcos et al., 1990; Byers e Schelling, 1993).

A menor concentração sérica de cálcio total nos animais de terceira lactação e a redução gradativa na concentração do cálcio ionizado, associadas ao aumento do número de lactações, provavelmente, decorre da maior eliminação desse elemento no leite, em conseqüência da maior produção de leite durante a segunda e a terceira lactações. Esse resultado assemelha-se ao de Mbassa e Poulsen (1991), que afirmaram existir alterações significativas nos eletrólitos plasmáticos devido à gestação e à lactação e são mais pronunciadas em animais com maior número de gestações e lactações.

A maior atividade da AST nas cabras de segunda lactação decorre da maior mobilização de gordura e do aumento de corpos cetônicos, que causam dano aos hepatócitos, e conseqüente extravasamento dessa enzima para o sangue circulante.

A diferença significativa e o maior valor da fosfatase alcalina nos animais de primeira lactação condizem com os achados de Halar et al. (1996), que encontraram valores mais elevados desta enzima no grupo de cabras jovens. Essa elevação justifica-se pelo fato de serem animais jovens em crescimento, que apresentam alta concentração de isoformas ósseas, próprias de animais jovens, e que se reduzem com a maturidade. Este resultado confirma o de Sarma e Ray (1985), ao afirmarem que o número de partos e a idade exercem influência na atividade da fosfatase alcalina.

A redução significativa observada nos valores das proteínas totais durante o estádio final da lactação decorre da discreta redução nos valores de albumina e globulinas (Tab. 3). Neste estádio da lactação, a maioria das cabras está gestante, necessitando de maior aporte protéico para suprir as funções de lactante e gestante.

O menor valor observado para a glicose em cabras no estádio inicial da lactação (Tab. 3) assemelha-se ao resultado encontrado por Forshell et al. (1991), que relataram redução da glicose sérica em vacas no estádio inicial da lactação. Segundo Fahey Júnior e Berger (1993), essa redução é conseqüência do grande consumo pelo feto no final da gestação e do gasto no início da lactação, que ocasionam balanço energético negativo durante o período.

A diferença e a menor concentração de triglicérides observada nos animais no estádio inicial da lactação são explicadas pelo maior consumo de lipoproteínas de muito baixa densidade (VLDL) pela glândula mamária no início da lactação, bem como pela menor disponibilidade de ácidos graxos livres para a produção de VLDL, em conseqüência de seu consumo para a produção de leite. Calcula-se que um terço dos ácidos graxos não esterificados circulantes dão origem a ácidos graxos de cadeia longa do leite (Byers e Schelling, 1993).

A redução dos valores séricos de magnésio no estádio final da lactação decorre do maior aporte desse mineral para manutenção da produção de leite e desenvolvimento do feto. Esse resultado confirma o de Ahmed et al. (2000), que observaram concentrações mais baixas de magnésio no sangue de cabras durante a gestação, devido à passagem desse elemento da mãe para o feto, favorecida por alteração fisicoquímica. Similarmente a produção de leite reduz o magnésio plasmático, daí a necessidade de mobilizar o magnésio dos sítios de origem para ser secretado no leite. Apesar da redução do magnésio no estádio final da lactação deste estudo, seu valor médio permaneceu dentro dos limites fisiológicos para a espécie, e não ocorreu quadro de hipomagnesemia raramente observada, porque as cabras têm grande capacidade de reduzir a excreção deste mineral, quando alimentadas com ração deficitárias neste elemento, o que impediu a ocorrência de deficiências séricas. 
Influência da ordem e estádios da lactação...

Tabela 3. Médias e desvios-padrão (DP) dos parâmetros bioquímicos séricos de cabras lactantes da raça Saanen, de acordo com o estádio da lactação

\begin{tabular}{|c|c|c|c|}
\hline \multicolumn{2}{|c|}{ Parâmetro bioquímico } & \multirow{2}{*}{$\begin{array}{c}\text { Inicio da lactação } \\
(\mathrm{n}=61)\end{array}$} & \multirow{2}{*}{$\begin{array}{c}\text { Final da lactação } \\
(n=62)\end{array}$} \\
\hline & & & \\
\hline Proteínas totais & $\mathrm{g} / \mathrm{dl}$ & $7,18 \pm 0,50 \mathrm{a}$ & $6,98 \pm 0,44 b$ \\
\hline Albumina (A) & $\mathrm{g} / \mathrm{dl}$ & $3,14 \pm 0,42 \mathrm{a}$ & $2,99 \pm 0,38 \mathrm{a}$ \\
\hline Globulinas (G) & $\mathrm{g} / \mathrm{dl}$ & $4,05 \pm 0,61 \mathrm{a}$ & $3,98 \pm 0,63 a$ \\
\hline Relação A/G & & $0,80 \pm 0,18 \mathrm{a}$ & $0,78 \pm 0,20 \mathrm{a}$ \\
\hline Glicose & $\mathrm{mg} / \mathrm{dl}$ & $51,14 \pm 5,47 b$ & $54,39 \pm 6,36 \mathrm{a}$ \\
\hline Uréia & $\mathrm{mg} / \mathrm{dl}$ & $52,37 \pm 12,38 \mathrm{a}$ & $53,33 \pm 12,96 a$ \\
\hline Triglicérides & $\mathrm{mg} / \mathrm{dl}$ & $13,25 \pm 5,29 b$ & $16,87 \pm 6,30 \mathrm{a}$ \\
\hline Colesterol & $\mathrm{mg} / \mathrm{dl}$ & $118,61 \pm 22,06 \mathrm{a}$ & $110,74 \pm 24,46 a$ \\
\hline Ácido úrico & $\mathrm{mg} / \mathrm{dl}$ & $0,34 \pm 0,13 \mathrm{a}$ & $0,34 \pm 0,16 \mathrm{a}$ \\
\hline Cálcio total & $\mathrm{mg} / \mathrm{dl}$ & $8,66 \pm 0,81 \mathrm{a}$ & $8,75 \pm 0,85 \mathrm{a}$ \\
\hline Cálcio ionizado & $\mathrm{mg} / \mathrm{dl}$ & $4,82 \pm 0,44 a$ & $4,96 \pm 0,49 a$ \\
\hline Fósforo & $\mathrm{mg} / \mathrm{dl}$ & $6,43 \pm 1,74 a$ & $6,47 \pm 1,42 \mathrm{a}$ \\
\hline Relação Ca/P & & $1,45 \pm 0,42 \mathrm{a}$ & $1,43 \pm 0,38 \mathrm{a}$ \\
\hline Ferro & $\mu \mathrm{g} / \mathrm{dl}$ & $122,97 \pm 28,78 \mathrm{a}$ & $130,41 \pm 35,63 \mathrm{a}$ \\
\hline Magnésio & $\mathrm{mg} / \mathrm{dl}$ & $3,12 \pm 0,48 \mathrm{a}$ & $2,96 \pm 0,35 b$ \\
\hline Sódio & $\mathrm{mEq} / 1$ & $142,75 \pm 2,86 a$ & $142,93 \pm 2,97 a$ \\
\hline Cloretos & $\mathrm{mEq} / 1$ & $106,22 \pm 2,25 \mathrm{a}$ & $106,74 \pm 2,71 \mathrm{a}$ \\
\hline Potássio & $\mathrm{mEq} / 1$ & $4,25 \pm 0,35 \mathrm{a}$ & $4,20 \pm 0,40 \mathrm{a}$ \\
\hline Amilase & $\mathrm{U} / 1$ & $26,29 \pm 8,17 \mathrm{a}$ & $23,85 \pm 8,45 a$ \\
\hline AST & $\mathrm{U} / 1$ & $109,86 \pm 36,59 a$ & $92,83 \pm 24,13 b$ \\
\hline ALT & $\mathrm{U} / 1$ & $19,93 \pm 3,41 \mathrm{a}$ & $18,78 \pm 3,09 \mathrm{a}$ \\
\hline Fosfatase alcalina & $\mathrm{U} / 1$ & $64,73 \pm 42,64 b$ & $82,74 \pm 48,68 \mathrm{a}$ \\
\hline GGT & $\mathrm{U} / 1$ & $37,47 \pm 12,39 a$ & $37,46 \pm 12,01 \mathrm{a}$ \\
\hline
\end{tabular}

$\mathrm{AST}=$ aspartato aminotransferase, $\mathrm{ALT}=$ alanina aminotransferase, GGT= gama glutamiltransferase.

Médias na linha seguidas de letras distintas diferem entre si $(\mathrm{P}<0,05)$.

A maior atividade da AST observada em animais no estádio inicial da lactação e sua redução com o avançar da lactação (Tab. 3), condizem com os achados de Mbassa e Poulsen (1991), que notaram maior atividade da enzima no estádio inicial da lactação. Esta maior atividade da AST é provavelmente conseqüência de esteatose hepática, associada à excessiva mobilização de gordura induzida pelo balanço energético negativo, de freqüente ocorrência durante o puerpério. Ressalta-se que uma suave ou moderada lipidose hepática pode resultar em aumento da atividade sérica das enzimas hepatoespecíficas, sem destruição de hepatócitos (Rukkwamsuk et al., 1999). Roussel et al. (1997) afirmaram que a atividade sérica da AST correlaciona-se com a lipidose hepática.
A razão para o incremento na atividade da fosfatase alcalina nas cabras em estádio final da lactação é a aumentada produção de isoenzimas ósseas relacionadas à intensa atividade osteoblástica durante o desenvolvimento fetal, visto que, em rebanhos submetidos a regime de manejo adequado, a grande maioria das cabras estará gestante nesse estádio da lactação.

\section{CONCLUSÃO}

Glicose, triglicérides, cálcio total, cálcio ionizado, magnésio, AST e fosfatase alcalina são biomarcadores eficazes para diagnosticar $\mathrm{o}$ desbalanço energético e mineral em cabras lactantes. 


\section{REFERÊNCIAS BIBLIOGRÁFICAS}

AHMED, M.M.M.; SIHAM, A. K.; BARRI, M. E. S. Macromineral profile in the plasma of Nubian goats as affected by the physiological state. Small Rumin. Res., v.38, p.249-254, 2000.

ANALISA Diagnóstica. Cálcio. In: Manual de produtos e técnicas. Belo Horizonte, 2000. p.28-31.

AVIDAR, Y.; DAVIDSON, M.; ISRAELI, B., et al. Factors affecting the level of blood constituents of Israeli dairy cows. Zentbl. Vet. Med. A., v.28, p.373-380, 1981.

BARROS, N.N.; MESQUITA, R.C.M.; SOUZA NETO, J.S. et al. Efeito de níveis de energia sobre a produção de leite em cabras da raça Anglo-nubiana. Pesq. Agropec. Bras., v.27, p.119-130, 1992.

BYERS, F.M.; SCHELLING, G.T. Los lipidos en la nutricion de los rumientes. In: $\mathrm{CHURCH}$, C. D. (Ed). El ruminante: fisiologia digestiva y nutrición. Zaragoza: Acribia, 1993. p.339-356.

CARLSON, P.G. Testes de química clínica. In: SMITH, B. (Ed). Tratado de medicina interna de grandes animais. São Paulo: Manole, 1994. v.1, p.395-423.

FAHEY JÚNIOR, G.C.; BERGER, L.L. Los carbohidratos en la nutrición de los ruminantes. In: CHURCH, C.D. (Ed). El ruminate: fisiologia digestiva y nutrición. Zaragoza: Acribia, 1993. p.305-337.

FORSHELL, K.P.; ANDERSSON, L.; PEHRSON, B. The relationships between the fertility of dairy cows and clinical and biochemical measurements, with special reference to plasma glucose and milk acetone. $J$. Vet. Med., v.38, p.608-616, 1991.

GOMIDE, C.A.; ZANETTI, M.A.; PENTEADO, M.V.C. et al. Influência da diferença cátionaniônica da dieta sobre o balanço, fósforo e magnésio em ovinos. Arq. Bras. Med. Vet. Zootec., v.56, p.363-369, 2004.

GONZÁLEZ, F.H.; SILVA, S. C. Introdução à bioquímica clínica veterinária. Porto Alegre: UFRGS, 2003. 198p.

HALAR, P.; HARUN, M.; AUGUSTO, L. et al. Blood profile of Mozambican goats in relation to physiological state. Isr. J. Vet. Med., v.51, p.1925, 1996.
INGRAHAM, R.H.; KAPPEL, L.C. Metabolic profile testing. Vet. Clin. N. Amer.: Food Anim. Pract., v.4, p.391-411, 1988.

KANEKO, J.J. Clinical biochemistry of domestic animals. 4.ed. San Diego: Academic, 1989. 932p.

KAPPEL, L.C.; INGRAHAM, R.H.; MORGAN, E.B. et al. Relationship between fertility and blood glucose and cholesterol concentrations in Holstein cows. Am. J. Vet. Res., v.45, p.26072612, 1984.

MARCOS, E.; MAZUR, A.; CARDOT, P. et al. The effect of pregnancy and lactation on serum lipid and apolipoprotein B and A-I levels in dairy cows. J. Anim. Physiol. Anim. Nutr., v.64, p.133$138,1990$.

MBASSA, G.K.; POULSEN, J.S.D. Influence of pregnancy, lactation and environment on some clinical chemical reference values in Danish Landrace dairy goats (Capras hircus) of different parity - I. Electrolytes and enzymes. Comp. Biochem. Physiol., v.100B, p.413-422, 1991.

McDOWELL, L.R. Minerais in animal and human nutrition. San Diego: Academic, 1992. $524 \mathrm{p}$.

RAVIART, I.; BÉZILLE, P.; BRAUN, J. P. et al. Profils biochimiques plasmatiques des chevreaus noveau-nés et des méres dans la période péripartum. Rec. Med. Vet., v.163, p.547-553, 1987.

ROUSSEL, J.A.; WHITNEY, S.M.; JOLE, J.D. Interpreting a bovine serum chemistry profile; part II. Vet. Med., v.92, p.559-566, 1997.

RUKKWAMSUK, T.; KRUIP, T.A.M.; WENSING, T. Relationship between overfeeding and overcondioning in the dry period and the problems of high producing dairy cows during the posparturient period. Vet. $Q$., v.21, p.71-77, 1999.

SARMA, P.V.; RAY, T.K. Effect of physiological states on some blood enzyme levels and its relation to milk production. Indian J. Dairy Sci., v.38, p.237-239, 1985. 